\title{
Ubiquitin-specific proteases as therapeutic targets for the treatment of breast cancer
}

\author{
Anupama Pal and Nicholas J Donato*
}

\begin{abstract}
Key mediators of signaling pathways in breast cancer involve post-translational protein modification, primarily mediated through phosphorylation and ubiquitination. While previous studies focused on phosphorylation events, more recent analysis suggests that ubiquitin plays a parallel and equally important role in several signaling and cell regulatory events in breast cancer. Availability of new tools capable of sensitive detection of gene mutations and aberrant expression of genes and proteins coupled with gene-specific knockdown and silencing protocols have provided insight into the previously unexplored ubiquitin regulatory process within these tumors. Ubiquitin-specific proteases are one class of enzymes with protein deubiquitinating activity, making up the majority of protein deubiquitinating diversity within mammalian cells. Ubiquitin-specific proteases are also emerging as potential therapeutic targets in many diseases, including cancer. In this report, we summarize the involvement of this class of enzymes in breast cancer signaling and cell regulation and illustrate the potential for additional studies to define novel targets and approaches in breast cancer therapy.
\end{abstract}

\section{Introduction}

Ubiquitination involves the covalent attachment of ubiquitin, a 76 amino acid protein, to numerous target proteins in a specific fashion to regulate their half-life, localization, activity and conformation [1,2]. Given the importance of ubiquitin-mediated changes in protein function and destruction, it is not by chance that the entire process is highly regulated as small changes in this cascade lead to pathologic consequences. Disruption of the ubiquitination cycle by mutations or modified expression of

\footnotetext{
* Correspondence: ndonato@med.umich.edu

Department of Internal Medicine, Division of Hematology/Oncology, University of Michigan Comprehensive Cancer Center, 1500 E. Medical Center Drive, Ann Arbor, MI 48109, USA
}

specific components within the cascade has been associated with cancer, diabetes, neurologic and developmental disorders [3,4]. Therapeutic potential thus exists for the identification of lesions within the ubiquitin cycle that can be targeted by small molecule-based approaches.

Ubiquitination is a multistep cascade catalyzed by at least three components - activation, conjugation and ligation - performed by ubiquitin-activating enzymes, ubiquitin-conjugating enzymes and ubiquitin ligases, respectively [1]. The initial research focus had been directed towards targeting the ubiquitin-activating enzymes, with activity described for small molecule inhibitors PYR-41 and PYZD-4409 [5,6]. However, additional targets have emerged that allow more selective pathway interference. MLN4924 is a small molecule inhibitor of NEDD8associated NAE enzyme activity that blocks neddylationdependent cullin-RING ubiquitin ligases to induce tumor cell apoptosis [6]. MLN4926 is currently being clinically evaluated. Efforts are underway to target ubiquitin-conjugating enzymes, as exemplified by development of the ubiquitin-conjugating enzyme hCdc34 inhibitor CC0651, which is currently in preclinical development [6]. Ubiquitin ligases provide more target specificity through their selective binding to protein substrates. Several ubiquitin ligases have been linked to cancer. The classic examples are MDM2 and IAPs, among others. There has been interest in developing inhibitors against MDM2 that regulate the expression levels of tumor suppressor and proapoptotic protein p53. Nutlin-3 and JNJ-26854165 are ubiquitin ligase inhibitors that are directed against MDM2 and are currently undergoing clinical evaluation as anticancer therapy [7]. In addition, small molecule inhibitor RITA (reactivation of p53 and induction of tumor cell apoptosis), Syl-155, RO5353, RO2468 and MI-63 are other inhibitors of MDM2 that show therapeutic potential that is being further investigated $[7,8]$. Seven IAP antagonists are also in phase I/phase II clinical trials [6]. However, specific efficacy of these inhibitors against one or more forms of breast cancer has not been described. 
Ubiquitination is reversible, like most regulatory processes, and the enzymes that reverse protein ubiquitination are collectively known as deubiquitinases (DUBs). The mammalian genome encodes around 100 DUBs categorized into five classes, four of which are thiol proteases including ubiquitin C-terminal hydrolases (UCHs), ubiquitin-specific proteases (USPs), ovarian tumor domain DUBs and machado Joseph domain DUBs. The fifth class is represented by JAB1/MPN metalloenzyme, which functions as a zinc finger metalloprotease [9].

DUBs play a crucial role in ubiquitin processing, reversal of ubiquitin signaling and recycling of ubiquitin [10]. Through their substrate-specific deubiquitinating activity, DUBs are implicated in the regulation of critical pathways including the internalization and degradation of receptor tyrosine kinases, activity and localization of signaling intermediates, gene transcription, cell cycle progression, apoptosis, chromosomal translocation and DNA damage repair [11-14]. Thus it is not surprising that defective DUB activity or expression has been associated with neurological disorders and cancer.

Since USPs represent a large and diverse subset of proteins with DUB activity, much of the research has focused on assessing their function, substrates and role in specific diseases. Overall assessment of gene mutations and overexpression of USPs in different cancer types coupled with their potential for small moleculemediated inhibition make USPs attractive as therapeutic targets, and there is growing interest in the development of USP-specific inhibitors as antiviral and anticancer agents. Since breast cancer represents a broad and diverse tumor type associated with a variety of genetic backgrounds, there is great potential for several USPs to play a role in this disease. This review examines USPs associated with breast cancer, highlights their known target actions and discusses their potential as targets in breast cancer therapy.

\section{Ubiquitin-specific protease-regulated signaling pathways implicated in breast cancer}

An important aspect that emerges from the USPs implicated in breast cancer is that they are critical regulators of transforming growth factor beta (TGF $\beta$ ) signaling, which has a well-documented role in mediating epithelial-tomesenchymal transition (EMT), tumor progression and metastasis in breast cancer [15]. Canonical TGF $\beta$ signaling involves ligand binding to heterodimeric complexes between TGF $\beta$ receptors I and II that activate the receptor Smads, Smad2/3, which then form complexes with Smad4 coreceptor and translocate to the nucleus, activating TGF $\beta$-dependent transcription [16]. The TGF $\beta$ signaling pathway can be regulated at multiple steps by various molecular regulatory mechanisms including ubiquitination of pathway molecules [17]. Several ubiquitin ligases such as NEDD4L and SMURF1 have been shown to attenuate TGF $\beta$ signaling by ubiquitinating Smad2 $[17,18]$. Smad7 is an inhibitory Smad that regulates TGF $\beta$ signaling by recruiting ubiquitin ligases such as SMURF1/2, WWP1 and NEDD4L to the TGF $\beta$ type I receptor, leading to its ubiquitin-mediated degradation and inhibition of TGF $\beta$ signaling $[17,18]$. The dichotomy of TGF $\beta$ signaling - that is, a tumor suppressor in normal cells and a tumor promoter in cancer cells - is not well understood [19]. The recent findings suggest that several DUBs may be key contributors to divergent TGF $\beta$ signaling and organization of the biologic response.

DUBs can regulate TGF $\beta$ signaling at the receptor, receptor-Smad or coreceptor-Smad level (Figure 1). USP11 and USP15 regulate TGF $\beta$ signaling through modulation of TGF $\beta$ receptor I levels [20,21]. USP11 binds to Smad7, which then recruits USP11 to TGF $\beta$ receptor I where it interacts, deubiquitinates and stabilizes TGF $\beta$ receptor I to sustain Smad-mediated TGF $\beta$ signaling [20]. USP15 binds to the Smad7-SMURF2 complex, which recruits USP15 to TGF $\beta$ receptor I and stabilizes it without direct binding [21]. USP4 is reported to directly interact and deubiquitinate TGF $\beta$ receptor I to regulate TGF $\beta$ signaling [22]. Inhibition of USP11, USP4 and USP15 blocks TGF $\beta$-mediated EMT and invasion in breast cancer [20-22]. Interestingly, AKT directly interacts and phosphorylates USP4, which then translocates from the nucleus to the plasma membrane where it stabilizes TGF $\beta$ receptor I through direct interaction [22]. AKT activation is associated with poor prognosis in breast cancer and inhibiting USP4 suppresses AKTmediated breast cancer cell migration [22]. USP4 has thus been proposed as an important determinant of crosstalk between TGF $\beta$ and AKT signaling in breast cancer.

Smad4 is the central transducer of TGF $\beta /$ bone morphogenetic protein (BMP) signaling. Smad4 regulation in the cell is not completely understood but phosphorylation-dephosphorylation has been ruled out as its primary regulatory mechanism. A recent report shows that USP9X modulates Smad4 levels in cells through reduction of its mono-ubiquitination. Smad4 mono-ubiquitination at K519 prevents its binding with phospho-Smad2, inhibiting TGF $\beta$ signaling [23]. USP9X reverses Smad4 ubiquitination to reactivate the pathway and reinstate TGF $\beta$ signaling. USP9X can thus regulate TGF $\beta$-mediated EMT and invasion through modulation of ubiquitinSmad4 levels. USP9X can also modulate ubiquitin ligase SMURF1, a negative regulator of TGF $\beta / B M P$ signaling that controls tumor cell migration and invasion by targeting Rho family proteins [24-26]. SMURF1 levels are tightly regulated in the cell through multiple mechanisms, including auto-ubiquitination, which targets SMURF1 for proteasomal degradation. USP9X was identified as a novel SMURF1 interacting protein that antagonizes 


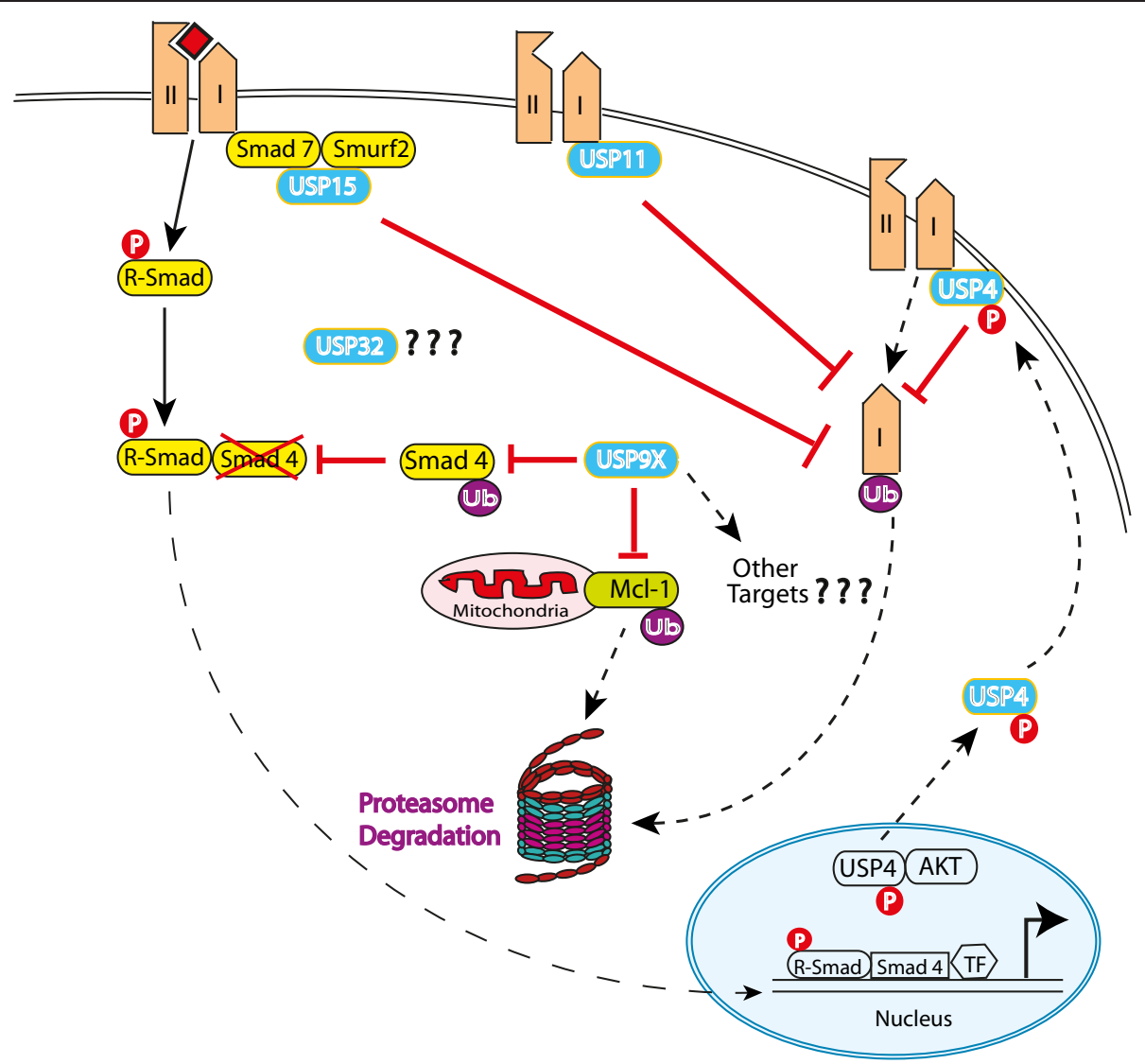

Figure 1 Regulation of transforming growth factor beta signaling by ubiquitin-specific proteases in breast cancer. Ubiquitin-specific proteases (USPS) overexpressed and implicated in breast cancer regulate transforming growth factor beta (TGF $\beta$ ) signaling at different levels in the signaling cascade. USP15, USP11 and USP4 inhibit TGF $\beta$ type I receptor degradation by preventing proteasomal destruction through deubiquitination and stabilization of TGF $\beta$ type I receptor, resulting in enhancement of TGF $\beta$ signaling. USP11 directly binds to the type I receptor whereas USP15 binds the receptor through complex formation with Smad7-Smurf2. USP4 also binds directly to the type I receptor but only when phosphorylated by AKT kinase. USP4 is phosphorylated in the nucleus by AKT kinase. Phosphorylated USP4 translocates to the membrane, binds and stabilizes type I receptor. TGF $\beta$ signaling can also be regulated at the coreceptor Smad level by USP9X. Smad4 mono-ubiquitination at K519 inhibits its binding with phospho-Smad 2 and thus inhibits Smad 4 and TGF $\beta$ signaling. Through its deubiquitinating activity, US9X reverses mono-ubiquitination and stabilizes Smad4, resulting in the sustained activation of TGF $\beta$ signaling. P, phosphorylation; TF, transcription factor; Ub, ubiquitin

SMURF1 auto-ubiquitination and destabilization. Importantly, depletion of USP9X in MDAMB231 metastatic breast cancer cells, which have elevated SMURF1 expression, inhibits SMURF1-dependent breast cancer cell motility [24]. USP9X-mediated regulation of TGF $\beta$ signaling even extends to neural development [27].

Various other breast cancer-related pathways have been shown to be regulated by DUBs. USP4 regulates tumor necrosis factor alpha-induced activation of NF- $\mathrm{kB}$ through deubiquitination-dependent downregulation of TGF $\beta$-activated kinase 1 (TAK1) [28]. Overexpression of USP4 inhibits TAK1-dependent NF- $\kappa B$ activation, whereas its knockdown is associated with enhanced tumor necrosis factor alpha-induced poly-ubiquitination of TAK1, Iк phosphorylation and NF-kB-dependent gene expression. USP11 has been shown to regulate tumor necrosis factor alpha-mediated NF- $\mathrm{kB}$ activation through modulation of
IKB $\alpha$ stability [29]. USP15 reverses the ubiquitinating activ-

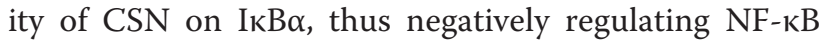
signaling [30].

\section{Ubiquitin-specific proteases overexpressed in breast cancer}

A list of USPs overexpressed in breast cancer is provided in Table 1.

\section{Ubiquitin-specific protease 15}

The USP15 gene is found amplified in around $2 \%$ of human breast tumors as well as other tumors, including ovarian and glioblastoma tumors [21]. Recent data implicate USP15 as an important regulator of cell cycle progression [31]. In glioblastomas, USP15 is reported to bind to the SMAD7-SMURF2 complex and stabilizes the TGF $\beta$ type I receptor through deubiquitination to 
Table 1 Ubiquitin-specific proteases overexpressed in breast cancer

\begin{tabular}{|c|c|c|c|c|}
\hline Deubiquitinase & Upregulated/downregulated & Breast cancer context & Implicated signaling & References \\
\hline \multirow[t]{2}{*}{ USP9X } & Upregulated & Human ductal carcinomas & TGF $\beta$ signaling & {$[23,42,43]$} \\
\hline & Upregulated & $\begin{array}{l}\text { Human breast cancer tissue as compared with the } \\
\text { adjacent normal tissue }\end{array}$ & & \\
\hline USP15 & Upregulated & Tissue microarray of 23 breast tumors & TGF $\beta$ signaling & {$[21,32]$} \\
\hline \multirow[t]{3}{*}{ USP32 } & Upregulated & Copy number alterations in ER + human breast tumors, & & \\
\hline & & $\begin{array}{l}50 \% \text { (nine of 18) of breast cancer cell lines and } 22 \% \\
\text { (nine of } 41 \text { ) of primary breast tumors compared with } \\
\text { mammary epithelial cells. }\end{array}$ & & {$[34,35]$} \\
\hline & & $\begin{array}{l}\text { USP32-CCDC49 expressed fusion gene in ER+, } \\
\text { tamoxifen-resistant breast cancer cell line ZR-75-30 }\end{array}$ & & \\
\hline USP9y, USP10, USP25 & Upregulated & $\begin{array}{l}\text { Human breast cancer tissue as compared with the } \\
\text { adjacent normal tissue }\end{array}$ & & [42] \\
\hline USP4 & Upregulated & $\begin{array}{l}\text { KD inhibits EMT, cell migration, invasion and metastasis } \\
\text { in human breast cancer cells in vitro and in vivo in } \\
\text { zebrafish xenograft metastasis model }\end{array}$ & TGF $\beta$ signaling & [22] \\
\hline USP11 & Upregulated & $\begin{array}{l}\text { KD inhibits TGF } \beta \text {-induced EMT in normal mouse } \\
\text { mammary epithelial cells (NMuMG) }\end{array}$ & TGF $\beta$ signaling & [20] \\
\hline
\end{tabular}

enhance TGF $\beta$ signaling [21]. USP15 is required for TGF $\beta$ mediated signaling and cell motility in the MDAMB231 metastatic breast cancer cell line [32]. Following TGF $\beta$ ligand stimulation in breast cancer cells, SMURF2 is degraded in a TRAF4-dependent manner that facilitates recruitment of USP15 to TGF $\beta$ receptor I to sustain TGF $\beta$ signaling. The TGF $\beta$ receptor-TRAF4 interaction triggers Lys63-linked TRAF4 poly-ubiquitination and subsequent activation of TAK1. TRAF4 is thus required for efficient TGF $\beta$-induced migration, EMT and breast cancer metastasis in a USP15-regulated fashion [33]. Most recently, USP15 was shown to stabilize MDM2 with impact on both p53 and the T-cell transcription factor NFATc. USP15 targeting may thus evoke both direct and indirect antitumor responses [7].

\section{Ubiquitin-specific protease 32}

The USP32 gene localizes on chromosome 17q23, which is commonly amplified in breast cancer. The interest in USP32 as a therapeutic target was generated following the study of Zhang and colleagues, which identified USP32 as the prognostic gene with copy number alterations in estrogen receptor-positive human breast tumors [34]. High USP32 transcript levels were also reported in $50 \%$ (nine of 18) of breast cancer cell lines and 22\% (nine of 41) of primary breast tumors compared with mammary epithelial cells [35]. Further, stable silencing of USP32 expression reduced proliferation and migration in the estrogen receptor-positive breast tumorigenic cell line, MCF7. Since USP32 mutations were not detected in this cell line, it appears that the increased USP32 levels are due to amplification of the wild-type USP32 gene [35]. The role of USP32 as a causal agent in breast cancer is further emphasized by a recent study that identified USP32-CCDC49 as one of the nine expressed fusion genes by structural analysis of the genome of ZR-75-30, an estrogen receptor-positive breast cancer cell line that has been used as a model system to study estrogen receptor-positive breast cancers that are insensitive to tamoxifen [36].

\section{Ubiquitin-specific protease 4}

USP4 has been reported to have higher expression levels in metastatic breast carcinomas as compared with the normal breast samples [22]. USP4 stimulates the TGF $\beta$ mediated EMT, invasion and metastasis. Depletion of USP4 in highly metastatic MDA-MB-231 breast cancer cells leads to the depletion of EMT markers and TGF $\beta$ induced migration in vitro, and in vivo in a zebrafish xenograft invasion metastasis model [22].

\section{Ubiquitin-specific protease 11}

USP11 was identified as a BRCA2-interacting protein [37]. BRCA2 is an important tumor suppressor gene that functions in double-strand DNA damage repair by homologous recombination [38]. Individuals with BRCA2 mutations are predisposed to breast cancer [39]. USP11 has been shown to be a contributing factor in the DNA damage repair functions in the BRCA2 pathway through direct interaction, but independent of BRCA2 deubiquitination [37]. USP11silenced cells show DNA damage repair activation even in the absence of any DNA damage and are hypersensitive to genotoxic stress-inducing agents including poly(ADP-ribose) polymerase inhibition and ionizing radiation [40]. These cells also show defective 
homologous recombination with misregulation of recruitment of double-strand break repair proteins including RAD51 and 53BP1 [37]. Underscoring the pro-survival role of USP11 in breast cancer, USP11 knockdown in normal mouse mammary epithelial cells (NMuMG) inhibited TGF $\beta$-induced EMT [20]. A recent study showed that breast cancer patients with high-level USP11 expression have higher rates of recurrence and poor survival outcomes when compared with low-level USP11 expressers [41].

\section{Other ubiquitin-specific proteases implicated in breast cancer: USP9X, USP10 and USP25}

An analysis of differential USP gene expression in breast cancer found greater than threefold overexpression of USP9X, USP10 and USP25 in human breast cancer tissue as compared with adjacent normal tissue [42]. Of these, USP9X is a well-characterized gene that has been shown to be a critical mediator of cell survival. Increased USP9X expression is reported in human follicular lymphoma and correlates with poor prognosis in multiple myeloma [43]. Some cancers, including primary breast cancer, demonstrate an association between USP9X and Mcl-1, a pro-survival BCL2 family member that is essential for stem and progenitor cell survival [43]. High Mcl-1 levels contribute to chemo-resistance and radio-resistance, contribute to disease relapse and correlate with poor prognosis in breast cancer and other cancers [44-46]. USP9X stabilizes $\mathrm{Mcl}-1$ by preventing its recognition by the proteasome, and USP9X knockdown sensitizes cells to killing by apoptosis-inducing drugs like the BH3 mimetic ABT-737 and by radiation $[43,47,48]$. Radiation and DNA-damaging agents are also more cytotoxic in colon cancer cells with full genetic disruption of the USP9X gene, but these effects are independent of $\mathrm{Mcl}-1$ stability [49]. Similarly, USP9X expression is required to maintain growth of glioblastomas and medulloblastomas, but USP9X-dependent growth does not appear to involve Mcl-1 stabilization [50]. The role of USP9X in breast cancer and its spectrum of breast cancer targets have not been studied $[23,42,43]$. This investigation may be particularly important because several mediators of breast cancer signaling and tumorigenicity, in addition to $\mathrm{Mcl}-1$, are regulated by USP9X.

USP10 was recently reported to be a novel regulator of cellular p53 [51]. USP10 deubiquitinates p53 and reverses MDM2-mediated nuclear transport and degradation of p53. Yuan and colleagues found diminished levels of USP10 in most renal cell carcinomas and the cell lines established from them, which lack p53 mutations. However, a small subset of renal cell carcinomas with p53 mutations contain elevated levels of USP10 that were found to exert an oncogenic activity in cultured tumor cells. USP10 functions to stabilize both wild-type and mutant p53, and in that context can act as a tumor suppressor or an oncoprotein [51]. This function should be considered in assigning a role for this DUB in breast cancer because many breast tumors, particularly those with triple-negative status, have mutations in $p 53$. USP10 also antagonizes c-myc transcription through deubiquitination of SIRT6, a histone deacetylase, and NF- $\mathrm{kB}$ signaling through deubiquitination of NEMO [52].

The function of USP25 in normal physiology and cancer is unknown, although recent studies suggest this protease plays a regulatory role in inflammation and innate immunity [53]. As with USP10, additional studies in breast cancer are needed for USP25.

\section{Small molecule inhibitor-mediated targeting of ubiquitin-specific proteases}

Several partial and specific inhibitors have been developed against USPs. HBX 41,108 is a partially-selective USP inhibitor that stabilizes p53 in HEK293 cells and induces caspase 3 and PARP cleavage in both $p 53^{+/+}$and $p 53^{-/-}$HCT-116 cells [54]. HBX 41,108 specificity is limited because it inhibits USP5, USP8, UCH-L3 and caspase 3 in addition to USP7, a DUB that was initially identified as the sole target of HBX 41,108 [54]. P5091 is a novel USP7-specific small molecule inhibitor that induces apoptosis in multiple myeloma cells resistant to conventional and bortezomib therapies through stabilization of p53. P5091 is an active antitumor agent in various tumor models [55]. b-AP15, also called VLX1500, is a proteasome inhibitor that inhibits the activity of the $19 \mathrm{~S}$ regulatory particle-associated DUBs, such as UCHL5, a ubiquitin C terminal hydrolase, and USP14 [55]. b-AP15 is shown to effectively inhibit tumor progression in multiple solid tumor mouse models and dissemination in acute myelogenous leukemia in vivo models [56]. Pimozide is a USP1 inhibitor that inhibits leukemic cell growth through degradation of ID1 proteins [57]. ML323 is a highly potent USP1 inhibitor with excellent selectivity against several DUBs that potentiates cisplatin cytotoxicity in nonsmallcell lung cancer and osteosarcoma cells [58].

WP1130 is a partially selective DUB inhibitor that has been developed in our laboratory. WP1130 induces apoptosis in cells through rapid accumulation of polyubiquitinated proteins. The known targets of WP1130 include USP5, USP9X and USP14, among others. We have shown previously that USP9X inhibition by WP1130 reduces MCL-1 levels, promotes apoptosis and increases tumor cell sensitivity to chemotherapy [59]. WP1130 was also shown recently to inhibit the growth of ERG-positive tumors in vitro and in mouse xenograft models of prostate cancer through inhibition of USP9X [5]. We have recently identified and developed a compound with improved specificity towards USP9X and antitumor activity in mouse 
models of myeloma, lymphoma and melanoma (unpublished data, Potu H and Donato NJ, 2014).

We have found that lentivirus-mediated USP9X knockdown in tumorigenic human breast cancer cell lines inhibits their growth. More importantly, USP9X knockdown in all triple-negative breast cancer cell lines tested causes apoptosis induction (unpublished data, Pal A and Donato NJ, 2014). In light of these findings, WP1130 and its derivatives could be significant as therapeutic modalities in the treatment of breast cancer.

\section{Conclusion}

USPs are a highly specialized and important class of DUBs with emerging therapeutic potential in breast cancer. Recent description of selective small molecule inhibitors for a small number of DUBs provides feasibility for targeting USPs for therapeutic purposes [60,61]. Targeting USPs as breast cancer treatment is especially promising due to the recent expansion of the role of several USPs in the regulation of various cancer-related pathways such as TGF $\beta$ signaling at multiple levels within the pathway. Thus, it is anticipated that therapeutic control of that pathway could be achieved with USP inhibitors, which may add to future treatment options for breast cancer patients.

\section{Abbreviations}

DUB: Deubiquitinase; EMT: Epithelial-to-mesenchymal transition; NF: Nuclear factor; TAK1: Transforming growth factor beta activated kinase 1;

TGFB: Transforming growth factor beta; UCH: Ubiquitin C-terminal hydrolase; USP: Ubiquitin-specific protease.

\section{Competing interests}

The authors declare that they have no competing interests.

\section{Acknowledgements}

NJD would like to acknowledge support from the Leukemia Lymphoma Society and the National Institutes of Health.

\section{Published online: 25 October 2014}

\section{References}

1. Hershko A, Ciechanover A: The ubiquitin system. Annu Rev Biochem 1998, 67:425-479.

2. Glickman $\mathrm{MH}$, Ciechanover A: The ubiquitin-proteasome proteolytic pathway: destruction for the sake of construction. Physiol Rev 2002, 82:373-428.

3. Shi D, Grossman SR: Ubiquitin becomes ubiquitous in cancer: emerging roles of ubiquitin ligases and deubiquitinases in tumorigenesis and as therapeutic targets. Cancer Biol Ther 2010, 10:737-747.

4. Dennissen FJA, Kholod N, van Leeuwen FW: The ubiquitin proteasome system in neurodegenerative diseases: culprit, accomplice or victim? Prog Neurobiol 2012, 96:190-207.

5. Yang Y, Kitagaki J, Dai RM, Tsai YC, Lorick KL, Ludwig RL, Pierre SA, Jensen JP, Davydov IV, Oberoi P, Li CC, Kenten JH, Beutler JA, Vousden KH, Weissman AM: Inhibitors of ubiquitin-activating enzyme (E1), a new class of potential cancer therapeutics. Cancer Res 2007, 67:9472-9481.

6. Xu GW, Ali M, Wood TE, Wong D, Maclean N, Wang X, Gronda M, Skrtic M, Li X, Hurren R, Mao X, Venkatesan M, Beheshti Zavareh R, Ketela T, Reed JC, Rose D, Moffat J, Batey RA, Dhe-Paganon S, Schimmer AD: The ubiquitin-activating enzyme E1 as a therapeutic target for the treatment of leukemia and multiple myeloma. Blood 2010, 115:2251-2259.
7. Zou Q, Jin J, Hu H, Li HS, Romano S, Xiao Y, Nakaya M, Zhou X, Cheng X, Yang P, Lozano G, Zhu C, Watowich SS, Ullrich SE, Sun SC: USP15 stabilizes MDM2 to mediate cancer-cell survival and inhibit antitumor $T$ cell responses. Nat Immunol 2014, 15:562-570.

8. Zhang Z, Chu XJ, Liu JJ, Ding Q, Zhang J, Bartkovitz D, Jiang N, Karnachi P, So SS, Tovar C, Filipovic ZM, Higgins B, Glenn K, Packman K, Vassiley L, Graves B: Discovery of potent and orally active p53-MDM2 inhibitors RO5353 and RO2468 for potential clinical development. ACS Med Chem Lett 2014, 5:124-127.

9. Nijman SMB, Luna-Vargas MPA, Velds A, Brummelkamp TR, Dirac AMG, Sixma TK, Bernards R: A genomic and functional inventory of deubiquitinating enzymes. Cell 2005, 123:773-786.

10. Baek $\mathrm{KH}$ : Conjugation and deconjugation of ubiquitin regulating the destiny of proteins. Exp Mol Med 2003, 35:1-7.

11. Priolo C, Tang D, Brahamandan M, Benassi B, Sicinska E, Ogino S, Farsetti A, Porrello A, Finn S, Zimmermann J, Febbo P, Loda M: The isopeptidase USP2a protects human prostate cancer from apoptosis. Cancer Res 2006 66:8625-8632

12. Oliveira AM, Chou MM, Perez-Atayde AR, Rosenberg AE: Aneurysmal bone cyst: a neoplasm driven by upregulation of the USP6 oncogene. J Clin Oncol 2006, 24:e1. author reply e2.

13. Cummins JM, Rago C, Kohli M, Kinzler KW, Lengauer C, Vogelstein B: Tumour suppression: disruption of HAUSP gene stabilizes p53. Nature 2004, 428:1. p following 486.

14. Stegmeier F, Rape M, Draviam VM, Nalepa G, Sowa ME, Ang XL, McDonald ER III, Li MZ, Hannon GJ, Sorger PK, Kirschner MW, Harper JW, Elledge SJ: Anaphase initiation is regulated by antagonistic ubiquitination and deubiquitination activities. Nature 2007, 446:876-881.

15. Nguyen DX, Bos PD, Massague J: Metastasis: from dissemination to organ-specific colonization. Nat Rev Cancer 2009, 9:274-284.

16. Massagué J, Gomis RR: The logic of TGF $\beta$ signaling. FEBS Letters 2006 580:2811-2820

17. Al-Salihi MA, Herhaus L, Sapkota GP: Regulation of the transforming growth factor $\beta$ pathway by reversible ubiquitylation. Open Biol 2012, 2:120082

18. Dupont $S$, Inui M, Newfeld SJ: Regulation of TGF- $\beta$ signal transduction by mono- and deubiquitylation of Smads. FEBS Lett 2012, 586:1913-1920.

19. Massagué J: TGF $\beta$ in cancer. Cell 2008, 134:215-230.

20. Al-Salihi MA, Herhaus L, Macartney T, Sapkota GP: USP11 augments TGFbeta signalling by deubiquitylating ALK5. Open Biol 2012, 2:120063.

21. Eichhorn PJ, Rodon L, Gonzalez-Junca A, Dirac A, Gili M, Martinez-Saez E, Aura C, Barba I, Peg V, Prat A, Cuartas I, Jimenez J, Garcia-Dorado D, Sahuquillo J, Bernards R, Baselga J, Seoane J: USP15 stabilizes TGF-beta receptor I and promotes oncogenesis through the activation of TGF-beta signaling in glioblastoma. Nat Med 2012, 18:429-435.

22. Zhang L, Zhou F, Drabsch Y, Gao R, Snaar-Jagalska BE, Mickanin C, Huang H, Sheppard KA, Porter JA, Lu CX, ten Dijke P: USP4 is regulated by AKT phosphorylation and directly deubiquitylates TGF-beta type I receptor. Nat Cell Biol 2012, 14:717-726.

23. Dupont S, Mamidi A, Cordenonsi M, Montagner M, Zacchigna L, Adorno M, Martello G, Stinchfield MJ, Soligo S, Morsut L, Inui M, Moro S, Modena N, Argenton F, Newfeld SJ, Piccolo S: FAM/USP9x, a deubiquitinating enzyme essential for TGFbeta signaling, controls Smad4 monoubiquitination. Cell 2009, 136:123-135.

24. Xie Y, Avello M, Schirle M, McWhinnie E, Feng Y, Bric-Furlong E, Wilson C, Nathans R, Zhang J, Kirschner MW, Huang SM, Cong F: Deubiquitinase FAM/USP9X interacts with the E3 ubiquitin ligase SMURF1 protein and protects it from ligase activity-dependent self-degradation. J Bio/ Chem 2013, 288:2976-2985.

25. Ebisawa T, Fukuchi M, Murakami G, Chiba T, Tanaka K, Imamura T, Miyazono K: Smurf1 interacts with transforming growth factor- $\beta$ type I receptor through Smad7 and induces receptor degradation. J Biol Chem 2001, 276:12477-12480.

26. Wang H-R, Zhang Y, Ozdamar B, Ogunjimi AA, Alexandrova E, Thomsen GH, Wrana JL: Regulation of cell polarity and protrusion formation by targeting RhoA for degradation. Science 2003, 302:1775-1779.

27. Stegeman S, Jolly LA, Premarathne S, Gecz J, Richards LJ, Mackay-Sim A, Wood SA: Loss of Usp9x disrupts cortical architecture, hippocampal development and TGFbeta-mediated axonogenesis. PloS One 2013, 8:e68287.

28. Fan YH, Yu Y, Mao RF, Tan XJ, Xu GF, Zhang H, Lu XB, Fu SB, Yang J: USP4 targets TAK1 to downregulate TNFalpha-induced NF-kappaB activation. Cell Death Differ 2011, 18:1547-1560. 
29. Sun $W$, Tan $X$, Shi $Y, X u$ G, Mao R, Gu X, Fan $Y, Y u$ Y, Burlingame $S$, Zhang $H$, Fu S, Cao G, Qin J, Yang J: USP11 negatively regulates TNFalpha-induced NF-kappaB activation by targeting on IkappaBalpha. Cell Signal 2010, 22:386-394.

30. Schweitzer K, Bozko PM, Dubiel W, Naumann M: CSN controls NF-kappaB by deubiquitinylation of IkappaBalpha. EMBO J 2007, 26:1532-1541.

31. Hayes SD, Liu H, MacDonald E, Sanderson CM, Coulson JM, Clague MJ, Urbe S: Direct and indirect control of mitogen-activated protein kinase pathway-associated components, BRAP/IMP E3 ubiquitin ligase and CRAF/RAF1 kinase, by the deubiquitylating enzyme USP15. J Bio/ Chem 2012, 287:43007-43018.

32. Inui M, Manfrin A, Mamidi A, Martello G, Morsut L, Soligo S, Enzo E, Moro S, Polo S, Dupont S, Cordenonsi M, Piccolo S: USP15 is a deubiquitylating enzyme for receptor-activated SMADs. Nat Cell Biol 2011, 13:1368-1375.

33. Zhang L, Zhou F, Garcia de Vinuesa A, de Kruijf EM, Mesker WE, Hui L, Drabsch Y, Li Y, Bauer A, Rousseau A, Sheppard KA, Mickanin C, Kuppen PJ, Lu CX, Ten Dijke P: TRAF4 promotes TGF-beta receptor signaling and drives breast cancer metastasis. Mol Cell 2013, 51:559-572.

34. Zhang Y, Martens JWM, Yu JX, Jiang J, Sieuwerts AM, Smid M, Klijn JGM, Wang Y, Foekens JA: Copy number alterations that predict metastatic capability of human breast cancer. Cancer Res 2009, 69:3795-3801.

35. Akhavantabasi S, Akman HB, Sapmaz A, Keller J, Petty EM, Erson AE: USP32 is an active, membrane-bound ubiquitin protease overexpressed in breast cancers. Mamm Genome 2010, 21:388-397.

36. Schulte I, Batty EM, Pole JC, Blood KA, Mo S, Cooke SL, Ng C, Howe KL, Chin SF, Brenton JD, Caldas C, Howarth KD, Edwards PA: Structural analysis of the genome of breast cancer cell line ZR-75-30 identifies twelve expressed fusion genes. BMC Genomics 2012, 13:719.

37. Schoenfeld AR, Apgar S, Dolios G, Wang R, Aaronson SA: BRCA2 is ubiquitinated in vivo and interacts with USP11, a deubiquitinating enzyme that exhibits prosurvival function in the cellular response to DNA damage. Mol Cell Biol 2004, 24:7444-7455.

38. Roy $R$, Chun J, Powell SN: BRCA1 and BRCA2: different roles in a common pathway of genome protection. Nat Rev Cancer 2012, 12:68-78.

39. Njiaju UO, Olopade Ol: Genetic determinants of breast cancer risk: a review of current literature and issues pertaining to clinical application. Breast J 2012, 18:436-442.

40. Wiltshire TD, Lovejoy CA, Wang T, Xia F, O'Connor MJ, Cortez D: Sensitivity to poly(ADP-ribose) polymerase (PARP) inhibition identifies ubiquitin-specific peptidase 11 (USP11) as a regulator of DNA double-strand break repair. J Biol Chem 2010, 285:14565-14571.

41. Bayraktar S, Gutierrez Barrera AM, Liu D, Pusztai L, Litton J, Valero V, Hunt K Hortobagyi GN, Wu Y, Symmans F, Arun B: USP-11 as a predictive and prognostic factor following neoadjuvant therapy in women with breast cancer. Cancer J 2013, 19:10-17.

42. Deng S, Zhou H, Xiong R, Lu Y, Yan D, Xing T, Dong L, Tang E, Yang H: Over-expression of genes and proteins of ubiquitin specific peptidases (USPs) and proteasome subunits (PSs) in breast cancer tissue observed by the methods of RFDD-PCR and proteomics. Breast Cancer Res Treatment 2007, 104:21-30.

43. Schwickart M, Huang X, Lill JR, Liu J, Ferrando R, French DM, Maecker $H_{\text {, }}$ O'Rourke K, Bazan F, Eastham-Anderson J, Yue P, Dornan D, Huang DC, Dixit VM: Deubiquitinase USP9X stabilizes MCL1 and promotes tumour cell survival. Nature 2010, 463:103-107.

44. Kitada S, Andersen J, Akar S, Zapata JM, Takayama S, Krajewski S, Wang H-G, Zhang X, Bullrich F, Croce CM, Rai K, Hines J, Reed JC: Expression of apoptosis-regulating proteins in chronic lymphocytic leukemia: correlations with in vitro and in vivo chemoresponses. Blood 1998, 91:3379-3389.

45. Wuilleme-Toumi S, Robillard N, Gomez P, Moreau P, Le Gouill S, Avet-Loiseau H, Harousseau JL, Amiot M, Bataille R: Mcl-1 is overexpressed in multiple myeloma and associated with relapse and shorter survival. Leukemia 2005, 19:1248-1252

46. Ding $Q$, He X, Xia W, Hsu J-M, Chen C-T, Li L-Y, Lee D-F, Yang J-Y, Xie X, Liu J-C, Hung MC: Myeloid cell leukemia-1 inversely correlates with glycogen synthase kinase- $3 \beta$ activity and associates with poor prognosis in human breast cancer. Cancer Res 2007, 67:4564-4571.

47. Trivigno D, Essmann F, Huber SM, Rudner J: Deubiquitinase USP9x confers radioresistance through stabilization of Mcl-1. Neoplasia 2012, 14:893-904.
48. Peddaboina C, Jupiter D, Fletcher $S$, Yap JL, Rai A, Tobin RP, Jiang W, Rascoe $P$, Rogers MK, Smythe WR, Cao X: The downregulation of Mcl-1 via USP9X inhibition sensitizes solid tumors to BCl-xl inhibition. BMC Cancer 2012, 12:541.

49. Harris DR, Mims A, Bunz F: Genetic disruption of USP9X sensitizes colorectal cancer cells to 5-fluorouracil. Cancer Biol Ther 2012, 13:1319-1324

50. Cox JL, Wilder PJ, Gilmore JM, Wuebben EL, Washburn MP, Rizzino A: The SOX2-interactome in brain cancer cells identifies the requirement of MSI2 and USP9X for the growth of brain tumor cells. PLOS One 2013, 8:e62857.

51. Yuan J, Luo K, Zhang L, Cheville JC, Lou Z: USP10 regulates $\mathrm{p} 53$ localization and stability by deubiquitinating p53. Cell 2010, 140:384-396.

52. Niu J, Shi Y, Xue J, Miao R, Huang S, Wang T, Wu J, Fu M, Wu ZH: USP10 inhibits genotoxic NF-kappaB activation by MCPIP1-facilitated deubiquitination of NEMO. EMBO J 2013, 32:3206-3219.

53. Zhong B, Liu X, Wang X, Li H, Darnay BG, Lin X, Sun SC, Dong C: Ubiquitin-specific protease 25 regulates TLR4-dependent innate immune responses through deubiquitination of the adaptor protein TRAF3. Sci Signal 2013, 6:ra35.

54. Colland F, Formstecher E, Jacq X, Reverdy C, Planquette C, Conrath S, Trouplin V, Bianchi J, Aushev VN, Camonis J, Calabrese A, Borg-Capra C, Sippl W, Collura V, Boissy G, Rain JC, Guedat P, Delansorne R, Daviet L: Small-molecule inhibitor of USP7/HAUSP ubiquitin protease stabilizes and activates p53 in cells. Mol Cancer Ther 2009, 8:2286-2295.

55. Peterson LF, Mitrikeska E, Giannola D, Lui Y, Sun H, Bixby D, Malek SN, Donato NJ, Wang S, Talpaz M: p53 stabilization induces apoptosis in chronic myeloid leukemia blast crisis cells. Leukemia 2011, 25:761-769.

56. Nocito A, Kononen J, Kallioniemi OP, Sauter G: Tissue microarrays (TMAs) for high-throughput molecular pathology research. Int J Cancer 2001, 94:1-5.

57. Chen J, Dexheimer TS, Ai Y, Liang Q, Villamil MA, Inglese J, Maloney DJ, Jadhav A, Simeonov A, Zhuang Z: Selective and cell-active inhibitors of the USP1/ UAF1 deubiquitinase complex reverse cisplatin resistance in non-small cell lung cancer cells. Chem Biol 2011, 18:1390-1400.

58. Liang Q, Dexheimer TS, Zhang P, Rosenthal AS, Villamil MA, You C, Zhang Q, Chen J, Ott CA, Sun H, Luci DK, Yuan B, Simeonov A, Jadhav A, Xiao H, Wang Y, Maloney DJ, Zhuang Z: A selective USP1-UAF1 inhibitor links deubiquitination to DNA damage responses. Nat Chem Biol 2014, 10:298-304.

59. Lo MC, Peterson LF, Yan M, Cong X, Hickman JH, Dekelver RC, Niewerth D, Zhang DE: JAK inhibitors suppress $t(8 ; 21)$ fusion protein-induced leukemia. Leukemia 2013, 27:2272-2279.

60. Edelmann MJ, Nicholson B, Kessler BM: Pharmacological targets in the ubiquitin system offer new ways of treating cancer, neurodegenerative disorders and infectious diseases. Expert Rev Mol Med 2011, 13:e35.

61. Colland F: The therapeutic potential of deubiquitinating enzyme inhibitors. Biochem Soc Trans 2010, 38:137-143.

doi:10.1186/s13058-014-0461-3

Cite this article as: $\mathrm{Pal}$ and Donato: Ubiquitin-specific proteases as therapeutic targets for the treatment of breast cancer. Breast Cancer Research 2014 16:461. 